\title{
FE MODELLING OF SFRC BEAMS UNDER IMPACT LOADS
}

\author{
Pegah Behinaein ${ }^{1}$, Ali A. Abbas ${ }^{2}$, Demetris M. Cotsovos ${ }^{3}$ \\ ${ }^{1} \mathrm{PhD}$ Student, Institute of Infrastructure and Environment, \\ Heriot-Watt University, Edinburgh EH14 4AS, UK \\ e-mail: pb2@hw.ac.uk \\ ${ }^{2}$ Senior Lecturer in Structural Engineering, School of Architecture, \\ Computing and Engineering, University of East London, London E16 2RD, UK \\ e-mail: abbas@uel.ac.uk \\ ${ }^{3}$ Assistant Professor, Institute of Infrastructure and \\ Environment, School of the Built Environment, Heriot-Watt \\ University, Edinburgh EH14 4AS, UK \\ e-mail: d.cotsovos@hw.ac.uk
}

Keywords: Steel-fibre-reinforced concrete, finite elements, dynamic analysis, brittle cracking, impact.

\begin{abstract}
The present work aims at investigating the structural behaviour of steel-fibrereinforced concrete (SFRC) beams under high-rate loading conditions mainly associated with impact problems. A simple, yet practical non-linear finite-element analysis (NLFEA) model was used in the study. The model is mainly focused on realistically describing the fully brittle tensile behaviour of plain concrete as well as the contribution of steel fibres to the postcracking response. The constitutive relations were incorporated into ABAQUS software brittle-cracking concrete model in order to adjust the latter to allow for the effects of fibres. Comparisons of the numerical predictions with their experimental counterparts demonstrated that the model employed herein, despite its simplicity, was capable of providing realistic predictions concerning the structural responses up to failure for different SFRC structural configurations. In the present study, the previous work is extended in order to numerically investigate the structural responses of simply-supported SFRC beams under impact loading. Data obtained from drop-weight tests on RC beams (without fibres) indicates that the response under impact loading differs significantly from that established during equivalent static testing. Essentially, there is (i) an increase in the maximum sustained load and (ii) a reduction in the portion of the beam span reacting to the impact load. However, there is considerable scatter making it difficult to ascertain the effect of loading rate on various aspects of RC structural response. To achieve this dynamic NLFEA is employed which is capable of realistically accounting for the characteristics of the problem at hand, a wave propagation problem within a highly non-linear medium. Following validation, a further study was conducted to assess the effect of steel fibers (provided at a dosage of Vf $=1 \%$ ) on key aspects of structural response such as maximum sustained load, load-deflection curves, deformation profiles and ductility) under different rates and intensities of impact loading. The predictions reveal that steel fibers can potentially increase the maximum sustained load, ductility, toughness exhibited by SFRC members under impact loading compared to their RC counterparts.
\end{abstract}




\section{INTRODUCTION}

The increasing demands for a variety of services and activities (i.e. faster transportation, higher energy production, safety, housing, etc.) has led to the increase in complex structural systems such as high-rise buildings, tunnels, bridges, slab-track for high-speed railways, offshore and marine structures, storage and industrial facilities and nuclear power plants. Such structures are fully or partially constructed form Reinforced Concrete (RC) and their behaviour is required to be characterised by an elevated level of resilience in order to safely withstand loads imposed at higher rates and intensities than those considered in current design codes. This has also resulted in - and highlighted the need for - the development of new advanced construction materials, such as steel fibres.

It has been established numerically [1-4] and experimentally [5-6] that the dynamic structural responses of RC elements differ to those observed under corresponding static loading once certain thresholds of applied loading rate are surpassed. The shift in structural response with increasing loading rates is considered to be associated with (a) structural arrangements (such as geometry, reinforcement and boundary details), (b) the brittle nature and triaxiality characterising concrete material behavior, (c) the nature of the problem at hand (i.e. a wave propagation problem within a highly nonlinear material) and (d) the development of high strain rates within concrete and steel which is widely considered to affect material behaviour (i.e. strain-rate sensitivity) [7]. The current work aim was to examine the potential benefits of introducing steel fibres to the concrete mix in order to enhance the responses of (the otherwise RC) structural elements under high rate loading due to impact. The work is based on dynamic Nonlinear Finite Element Analysis (NLFEA), which was initially validated using exiting experimental data to ascertain its accuracy before the subsequent parametric studies were carried out. The work builds on previous NLFEA-based studies on various SFRC structural configurations subjected to both static monotonic and cyclic loading (the specimens covered a wide practical range from simply-supported beams to more complex structural systems characterised by a certain degree of static indeterminacy, such as continuous columns and beamcolumn sub-assemblages) [8-11]. Both previous and current studies utilize a material model for SFRC that is focused on realistically describing the fully brittle tensile behaviour of plain concrete as well as the contribution of steel fibres to the post-cracking response. The constitutive relations were incorporated into ABAQUS software brittle-cracking concrete model [12] in order to allow for the effects of fibres. The previous work (particularly under seismic loading) is extended herein in order to realistically describe the response - up to failure - of SFRC structural simply-supported beams under high-rate (i.e. impact) loading. The ultimate aim is to form the basis of a new practical assessment and design method for SFRC under impact.

The history of fibre-reinforced materials started in ancient Egypt over 2000 years ago with mud bricks reinforced with straw fibres. In more recent times, alternative fibres were introduced in the 1960s, such as steel, glass, and synthetic fibres such as polypropylene fibres etc. Early investigation into the application of steel fibre-reinforced concrete (SFRC) was carried out by Romualdi and Batson [13] resulted in its application in the pavement construction. 
Since then, fibres have become widely adopted in different structural applications, for instance in concrete pipes, pavement slabs and more recently, it has been used in suspended slabs [14]. The introduction of steel fibres into the concrete mix can also lead to a reduction of transverse (i.e. shear) reinforcement such as beams, walls, joint regions [8-11, 15] without compromising design codes $[16,17]$ performance requirements for strength and ductility. The main benefit of such reduction is to alleviate reinforcement congestion due to dense arrangement and spacing of shear links in the critical regions of RC structures, as dictated in design codes such as the Eurrocode 8 for seismic-resistant design [17] in order to avoid brittle failure modes. The present research work focuses on the behaviour of steel fibres and other types are outside the scope of this study.

\section{METHOD}

\subsection{Background of SFRC impact tests}

To date, a number of drop weight tests have been conducted on SFRC specimens [18-20]. The majority of these studies employ drop weight testing, in which a steel striker is allowed to fall from a pre-defined height onto a specific (usually the mid-span) region of the structural element considered such as beams and slabs. A wide range of SFRC specimens have been tested to date under impact loading in order to assess the effect of various parameters associated with the fibres used (e.g. shape, aspect ratio, content) on the exhibited behaviour. The data obtained reveals that fibres capable of developing more adhesive and frictional bond as well as more effective anchorage at their ends can increase the maximum sustained load, ductility, toughness and crack controllability exhibited by SFRC members under impact loading compared to their counterparts exhibited by conventionally reinforced RC members [19]. However, it should be noted that the data is characterized by considerable scatter severely reducing its usefulness in accurately quantifying the above effects. The scatter predominantly reflects the difficulty in correlating the measured response to the actual physical state of the specimens. In fact, the measured maximum value of imposed load frequently corresponds to a specimen physical-state characterized by high concrete disintegration as well as low residual load-bearing capacity and stiffness [2,21].This stage of structural response has little practical significance as it depends heavily on post-failure mechanisms for transferring the applied loads to the specimen supports. In view of the above, the available test data cannot provide detailed insight into the mechanisms underlying structural response. It can, however, provide a qualitative description of the effect of loading-rate on specimen behaviour.

\subsection{Limitations of existing NLFEA software packages}

NLFEA can be used in a safer and more cost-efficient manner for investigating a wider range of problems than those studied experimentally. It is capable of providing realistic predictions and more detailed insight into the mechanisms underlying SFRC structural responses under high-rate loading. However, as it usually employs dense three-dimensional (3D) finite element meshes combined with complex constitutive material laws implemented through the 
use of iterative solution strategies, the required computational resources are high. As a result, its use is generally limited for the analysis of relatively simple structural forms. Moreover, its ability for providing realistic predictions of structural behaviour is, in most cases, linked with the use of case-study dependent constitutive models [22] often incorporating empirical amplification factors to account for the effect of strain-rate sensitivity on concrete material behaviour. This apparent lack of generality is the main drawback of NLFEA for RC structures, the results of which are often treated with some doubt regarding the validity of the predictions obtained.

\subsection{General aspects of the FE model adopted}

A finite-element (FE) model is generally considered capable of yielding realistic predictions of the nonlinear response of concrete structures when the deviation of the predicted values from their experimentally-measured counterparts (of structural characteristics considered) does not exceed a value in the order of $20 \%$ [22, 23]. Such structural characteristics usually include the load-bearing capacity, the relation between applied load and corresponding displacements, reactions and first-order deformation derivatives, i.e. rotations.

The present work is based on the use of the well-known commercial FE analysis software ABAQUS [12], which is capable of carrying out 3D static and dynamic NLFEA which incorporates a simple brittle model (termed "brittle cracking model") in order to describe concrete material behaviour. It is purpose-built for materials the behaviour of which is dominated by tensile cracking [12]. This is largely true in the case of RC flexural structural elements where cracks form due to the development of tensile strains within the concrete medium. Such cracks gradually extend with increasing levels of applied loading, ultimately leading to structural failure and collapse. This is particularly useful for the present study on SFRC performance as it allows for modelling the effect of steel fibers on the concrete behaviour in tension, especially after the onset of cracking. It is interesting to note that in the "brittle cracking model", the behaviour of concrete in compression is modelled as being linear elastic which safeguards the numerical stability of the solution process. By adopting this simplification, emphasis is focused on realistically describing the all-important tensile response. Furthermore, as the present NLFEA is carried out using 3D modelling, at least one principal stress is required to be tensile to trigger cracking (this is the salient feature of concrete behaviour which is predominantly brittle) and this is well captured by the brittle cracking model. So although the model assumes elastic behaviour in compression for efficiency purposes, this does not affect the accuracy as the predictions are in good agreement with experimental data (as discussed in the present study). So in summary, the brittle cracking model focuses on the important fundamental parameters affecting concrete behaviour (i.e. brittleness and cracking). This basic yet profound and focused approach allows one to develop a more fundamental understanding of aspects affecting the structural response of SFRC. 


\subsection{Material modelling}

The introduction of fibres into the concrete mix can enhance both the concrete material behaviour (predominantly in tension) and RC structural response. More specifically fibres attribute ductile characteristics to concrete material behaviour resulting in an increase in strength, toughness and ductility. To date, many experimental investigations have been conducted on the effect of fibers on structural concrete material behaviour. The vast majority of these tests have been carried out on prisms and cylinders subjected to compression, direct and indirect tension and flexure. Such studies aim at assessing the effect of fibers on:

- important aspects of concrete material behaviour such as compressive strength $f_{c}$, tensile strength $f_{t}$, the elasticity modulus $E_{c}$, and the stress-strain curve under uniaxial compression or tension after cracking, and

- the cracking process that fibrous concrete undergoes, which is dependent on the fibre content, the strength and pull out behaviour of fibres bridging a crack as the crack becomes wider with increasing levels of applied loading.

The performance of SFRC is influenced by a number of parameters associated with the fibres such as shape, length, aspect ratio, and volume fraction [24, 25] and the concrete mix. The effect of fibres on concrete material behaviour in tension can be mainly observed after the onset of cracking as they attribute ductile characteristics to the post cracking behaviour of SFRC compared to the fully brittle behaviour exhibited by plain concrete [23, 26, 27]. Depending on the type and amount of fibres used, the post cracking behaviour may be described as strain-softening or strain-hardening. The residual strength of SFRC is the result of steel fibers bridging the cracks and the bond between the fiber and the surrounding concrete. The small use of fibers concrete mix results in softening post-cracking response and failure is caused by breaking fibers as they bridge the cracks. Using higher values of fiber-content results in a softening post-cracking behaviour, but exhibiting more ductile characteristic and in some cases with using higher fiber content, a strain-hardening response is observed as the fibers undertake the tensile forces which are acting normal to the plane of crack and will cause the increase in tensile strength.

\subsection{Nonlinear solution strategy}

During each time step the equation of motion governing the nonlinear dynamic impact problem considered is solved as a sequence of equivalent static problems through the use of the Newmark family of approximation methods. At the beginning of each iteration and based on the values of displacement, velocity and acceleration obtained from the previous iteration, the effective stiffness and load matrix are calculated and an equivalent static problem is formulated [27]. The equivalent static problem is solved through an iterative procedure based on a modified Newton-Raphson method [23]. During the solution process of the equivalent static problem every Gauss point is checked to determine whether loading or unloading takes place and to establish whether any cracks close or form. Depending on the results of the previous 
checks, changes are introduced to the stress-strain matrices of the individual FE's and to the stiffness matrix of the structure. Convergence is checked locally at each Gauss point; this involves the use of the constitutive relations for the calculation of the stresses increments which correspond to the estimated values of the strain increments. Once the values of the strain and the corresponding stress increments become less than a small predefined value (i.e. convergence criterion) then convergence is accomplished. When this is not achieved, the residual forces are calculated and are then re-imposed onto the FE model of the RC form investigated until convergence is finally achieved.

\subsection{Modelling of cracking}

The cracking process that concrete undergoes is modelled through the use of the smeared crack approach $[23,27,28]$. A crack is considered to form when the predicted stress in a given part of the structure corresponds to a point in the principal stress space that lies outside the surface defining the failure criterion for concrete, thus resulting in localised failure of the material. The plane of the crack is assumed normal to the direction in which the smallest principal stress acts (smallest compressive or largest tensile stress). A simple Rankine failure criterion is used to detect crack initiation (i.e. a crack forms when the maximum principal tensile stress exceeds the specified tensile strength of concrete). Constitutive calculations are performed independently at each integration point of the finite element model. The presence of cracks enters into these calculations by the way in which the cracks affect the stress and material stiffness associated with the integration point. After crack formation the residual shear stiffness along the plane of the crack is determined through the use of a shear retention factor. Its value is affected by the presence of the fibres bridging the two sides of the crack. The shear stiffness is considered to decrease as cracks widen. Therefore, in order to allow for degradation in shear stiffness due to crack propagation, the shear modulus is reduced linearly form full shear retention (i.e. no degradation) at the cracking strain to $50 \%$ of that at the ultimate tensile strain. It is worth noting that the shear retention does not diminish altogether due to the presence of the fibres which enhance dowel action as well as aggregate interlock by reducing crack opening. Crucially, the fibres contribute to shear resistance by providing tensile resistance (across the crack) to the shear induced diagonal tension stresses.

\subsection{Structural forms investigated}

The behaviour of the RC beam specimens considered herein has been experimentally investigated by Hughes and Spiers [29] under static and impact loading. The design details of the specimens (C2) investigated numerically in the present study are depicted in Figure1. The modulus of elasticity $E_{S}$, the yield stress $f_{y}$ and the ultimate strength $f_{u}$ of both the longitudinal and transverse reinforcement bars are $206 \mathrm{GPa}, 460 \mathrm{MPa}$ and $560 \mathrm{MPa}$, respectively. The uniaxial compressive strength $f_{c}$ of concrete is $45 \mathrm{MPa}$. The beams were subjected to drop weight testing at their mid-spans. Mild steel, rubber or ply pads were placed on the top face of the specimen in order to prevent or moderate local damage in the impact area and to some extent control the rate of loading. 


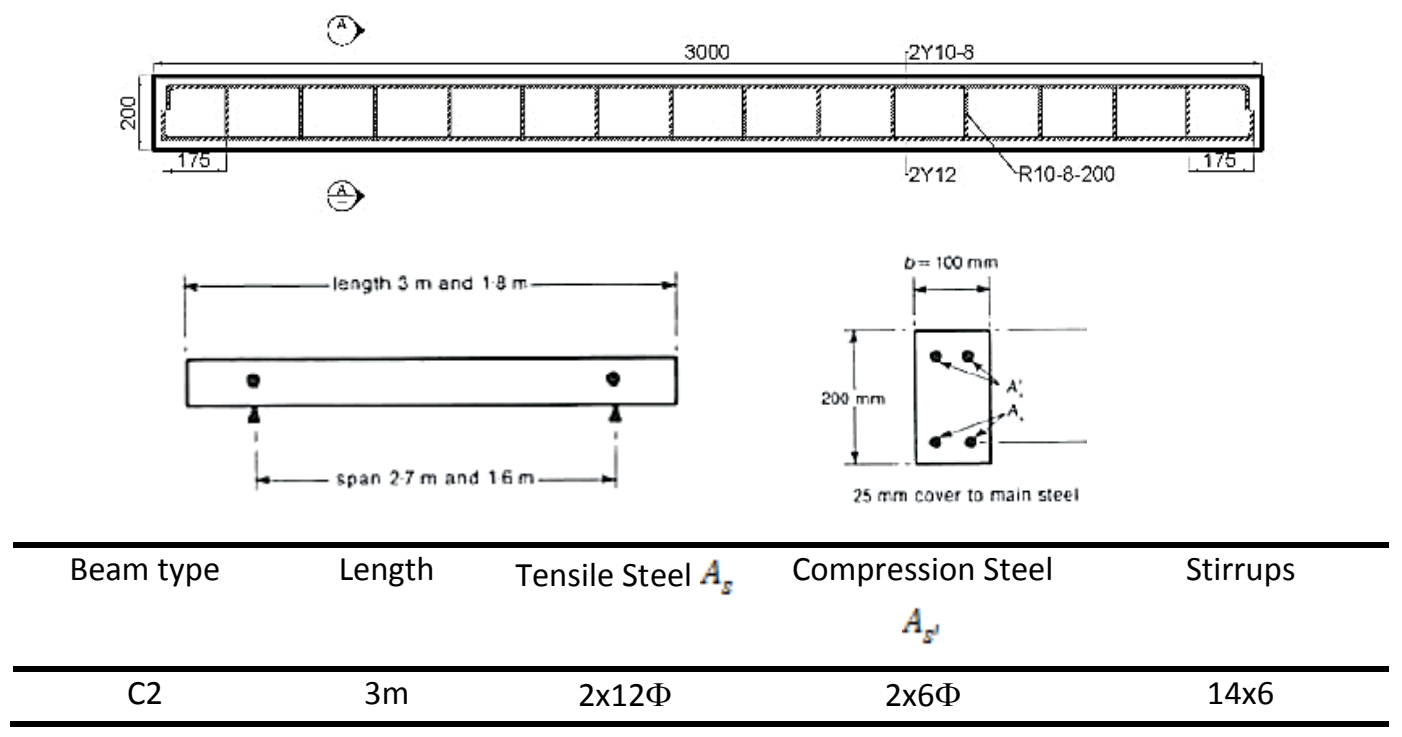

Figure 1: Arrangements of RC beam investigated, adopted from Hughes and Spiers [29]

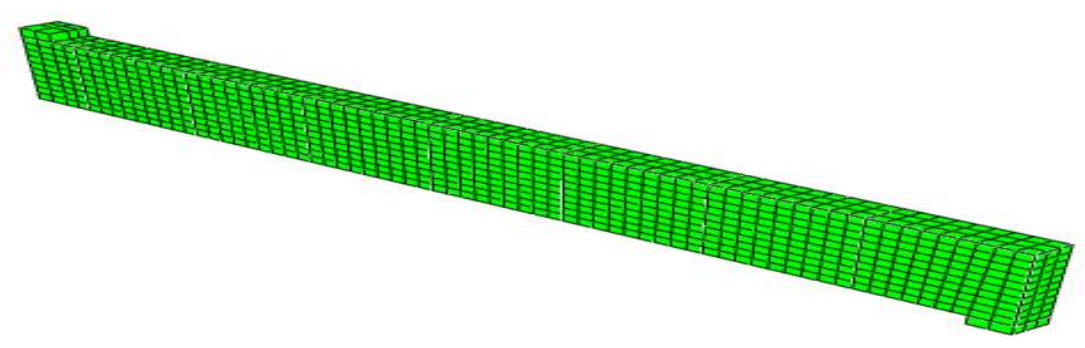

Figure 2: FE mesh adopted

\section{RESULTS AND DISCUSSION}

\subsection{Numerical predictions}

Initially, the case of RC beam specimen (C2) tested by Hughes and Spiers [29] was modelled using NLFEA under both static and dynamic (i.e. high-rate/impact) loading and subsequently a further study was carried out by adding fibres to this specimen in order to study SFRC under impact. Different loading rates were considered in the numerical study ranging from 10 to $1000 \mathrm{kN} / \mathrm{msec}$, which were applied once monotonically and then in the form of a pulse load. The pulse load was applied in different stages, initially using the value of the maximum load sustained monotonically and consequently that load was reduced every time by $10 \%$ (of the maximum monotonic load sustained). The reduction continued in this manner to the point that the beam can bear the applied load, as shown in Figure 3(a). The aim was to establish the actual load-carrying capacity as the load applied during the experimental testing led to the complete destruction of the specimen and hence was not useful in determining the load-carrying capacity of the specimen. This is a common shortcoming of experimental testing under high rates of loading and limit its usefulness in terms of design, where a containment is needed up to a certain load threshold. To address this, the NLFEA-based study considered applying in the reduced pulse manner described in order to help pinpoint the actual failure point and establish the all-important load-carrying capacity value. 
The variation of the dynamic increase factor (DIF) was considered as depicted in Figure 3(b), i.e. the maximum load sustained by the RC beams under high rate loading normalised with respect to its counterpart under static loading $\max P_{d} / \max P_{s}$, which shows a good correlation between the experimental and numerical results. Another indicator of the DIF was also considered, namely the ratio between the maximum displacement at mid-span under the dynamic load and the displacement under static load Max $\delta d / M a x \delta s$. Both NLFEA-based $\max P_{d} / \max P_{s}$ and $\operatorname{Max} \delta d / M a x \delta s$ values at different loading rates as depicted in Figure 4(a,b), which shows that an increase in the loading rate leads to an increase in stiffness and loadcarrying capacity combined with a decrease of the maximum deflection at mid-span. As regards the cracking and deformation profiles, Figures 5 and 6 indicate that, as the rate of loading increases, the length portion $\left(L_{\text {eff }}\right)$ of the beam mostly affected by the applied load reduces. For relatively high rates of loading, this effective length is confined in the region of the beam mid-span extending on either side of the mid-span cross section to a distance marked by the formation of vertical flexural cracking initiating at the upper face and extending downwards, whereas the remainder of the beam (i.e. the portions extending between the supports and the aforementioned cracking) remains practically unaffected by the applied load. Therefore, under high rates of loading, the beam behaviour is essentially characterized by $L_{\text {eff. }}$.

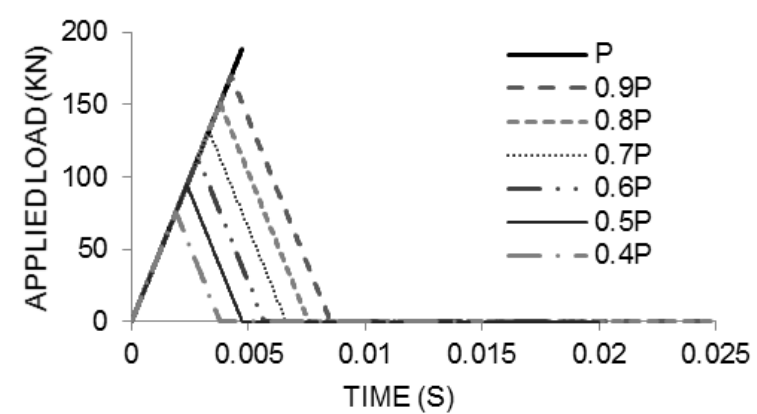

(a)

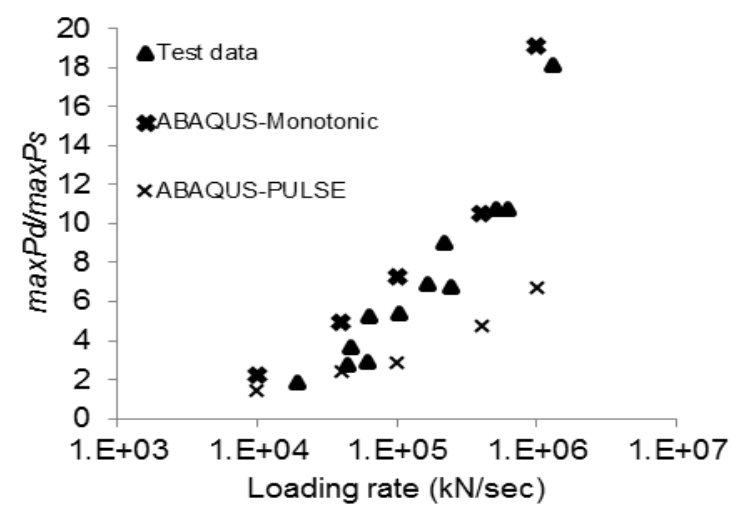

(b)

Figure 3: (a) Applied load time history for monotonic and pulse load for RC and (b) comparison of experimental and numerical results for $\max P_{d} / \max P_{s}$ for different monotonic and pulse loading rates
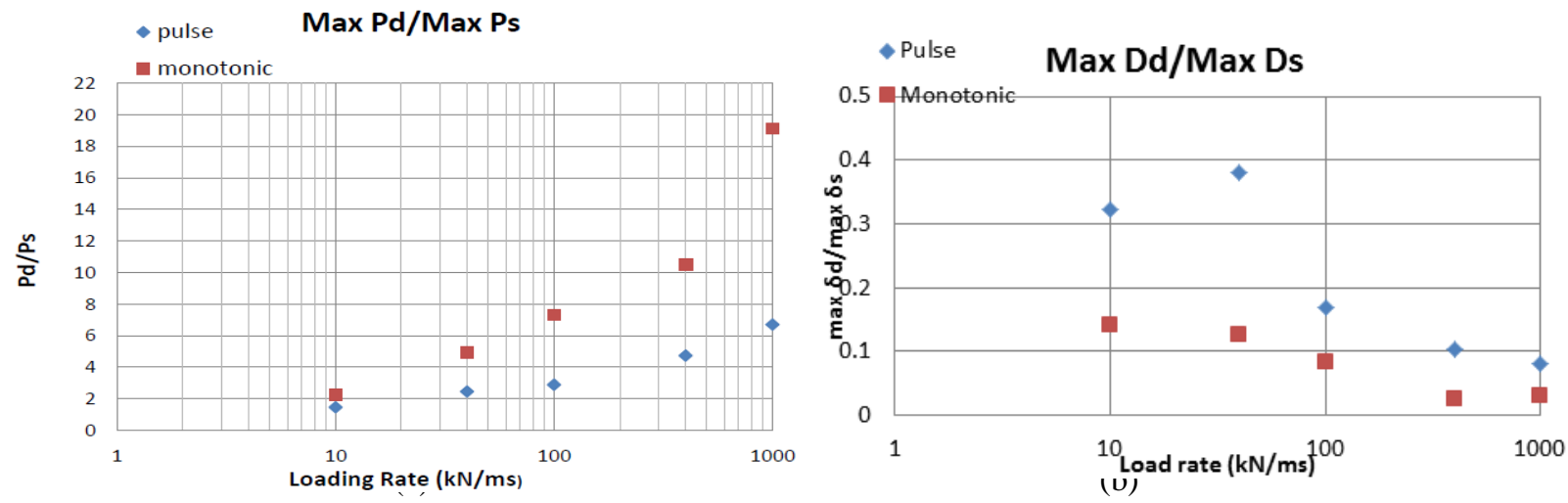

Figure 4: Comparison of NLFEA-based (a) $\max P_{d} / \max P_{s}$ and (b) $\operatorname{Max} \delta d / M a x \delta s$ for different monotonic and pulse loading rates for RC beam 


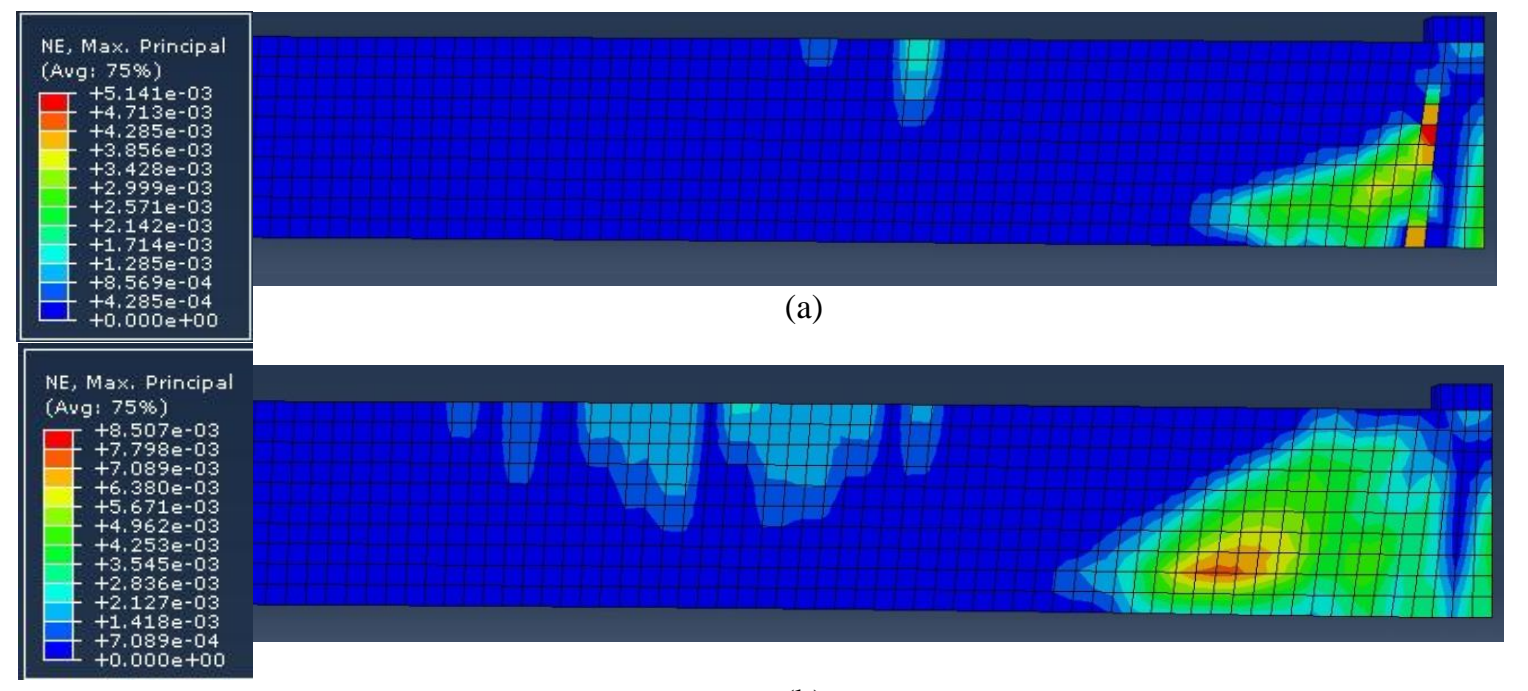

(b)

Figure 5: Strain distribution along the RC beam for loading rate $100 \mathrm{kN} / \mathrm{msec}$ at (a) $75 \%$ and (b) $100 \%$ of load
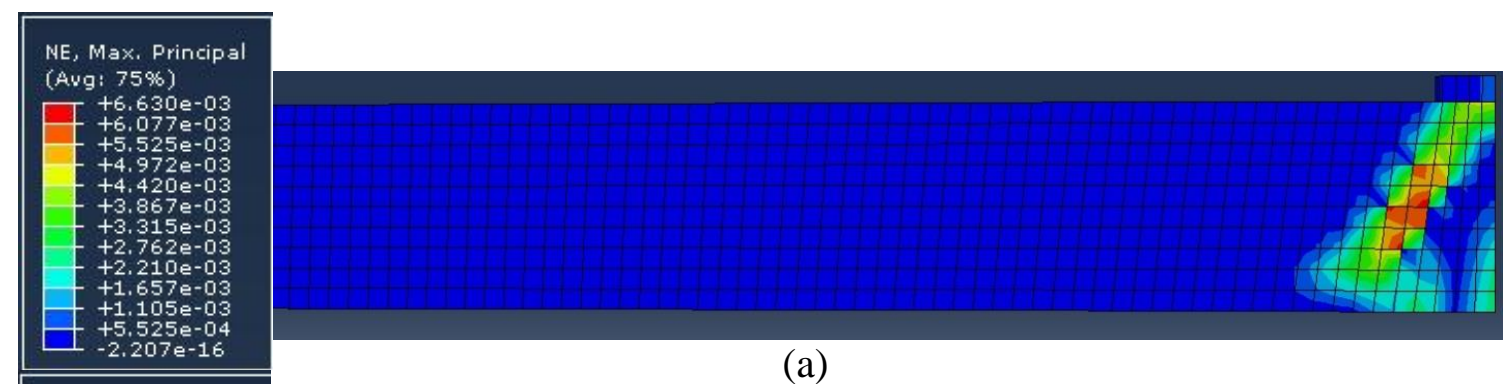

(a)
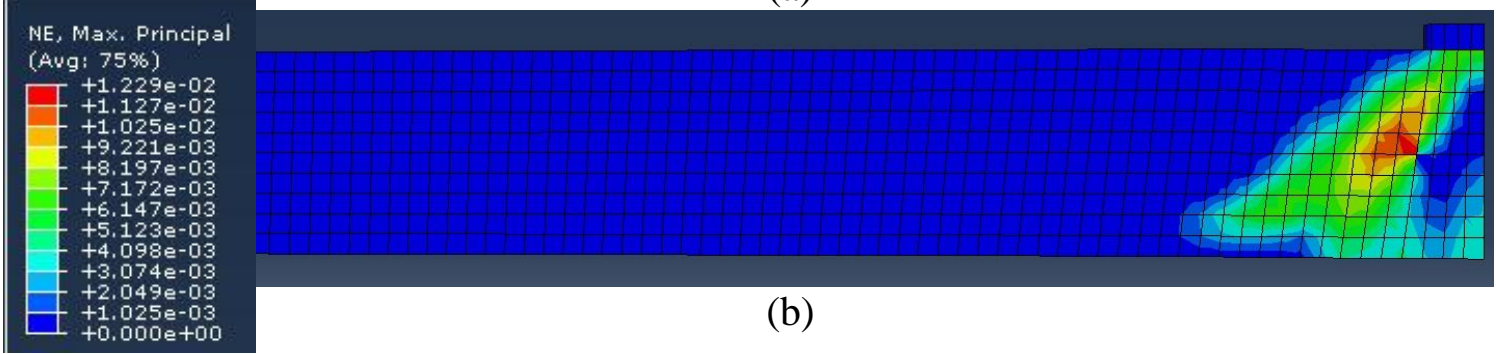

(b)

Figure 6: Strain distribution along the RC beam for loading rate $1000 \mathrm{kN} / \mathrm{msec}$ at (a) $75 \%$ and (b) $100 \%$ of load

\subsection{SFRC beam}

Following the study of the RC beam (specimen $\mathrm{C} 2$ ), which also served to validate the $\mathrm{FE}$ model and strategy used, steel fibres were added with a volume fraction $\left(V_{f}\right)$ value of $1 \%$. The aim of this NLFEA-based study is to enhance understanding of the effect of steel fibers on structural behavior of RC elements under low and high rates of loading. The material constitutive model proposed by Lok and Xiao [30] was adopted in order to define the post-cracking tensile stress-strain relationship for SFRC. The load-deflection results under static loading are presented alongside the ones for RC beams (i.e. without fibres) in Figure 7. The curves are obtained based on incremental displacement acting on the mid-span of the beam. As it is shown, by adding $1 \%$ steel fibers to the concrete matrix, both the load carrying capacity and displacement in the mid-span of the beam increase. A comparison between the ratios of maximum dynamic to static load carrying capacity for different rates of loading $\left(\max P_{d} / \max P_{s}\right)$ and maximum dynamic to static displacement (MaxDd/MaxDs), for both RC and SFRC are 
shown in Figures $8(\mathrm{a}, \mathrm{b})$, respectively. An increase in load carrying capacity and maximum deflection in the mid span of the beam is observed for SFRC compared to RC counterparts. Similar trends were found when the loading was applied as a pulse as can be seen in Figure $9(a, b)$ indicating the potential benefits of fibres in design terms as the load-bearing capacity increases. Figures $10(a, b)$ and 11(a,b) indicate that the fibres help widen the localised zone affected by the load $\left(L_{\text {eff }}\right)$, albeit this still decreasing as the loading rate increases.

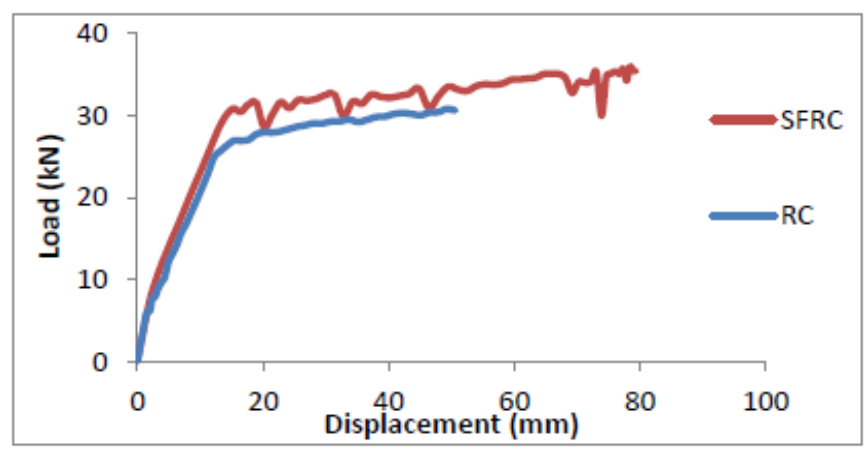

Figure 7: Comparison of static load-deflection in the middle of the beam for SFRC and RC

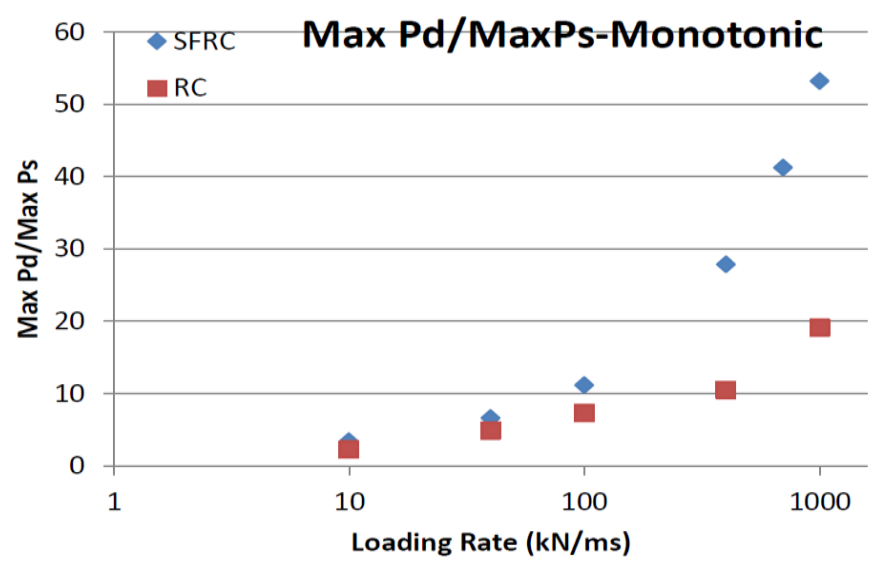

(a)

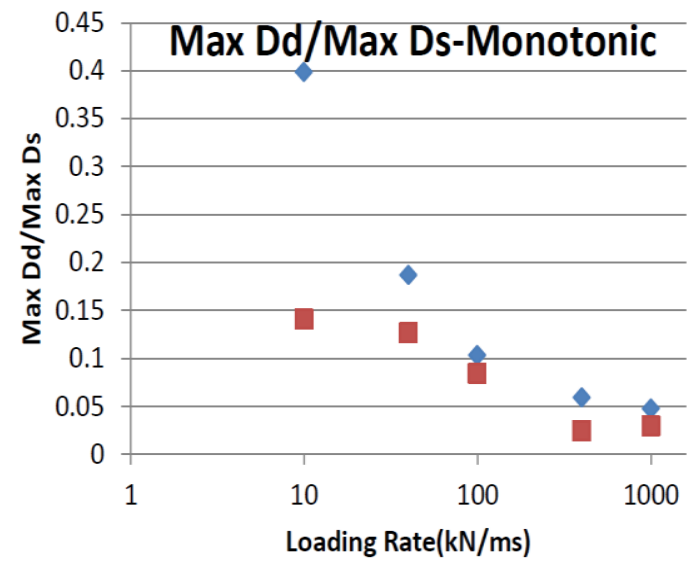

(b)

Figure 8: (a) Comparison of MaxPd/MaxPs for RC and SFRC, and (b) Comparison of Max $\delta d / M a x \delta s$ for RC and SFRC under monotonic load at different loading rates

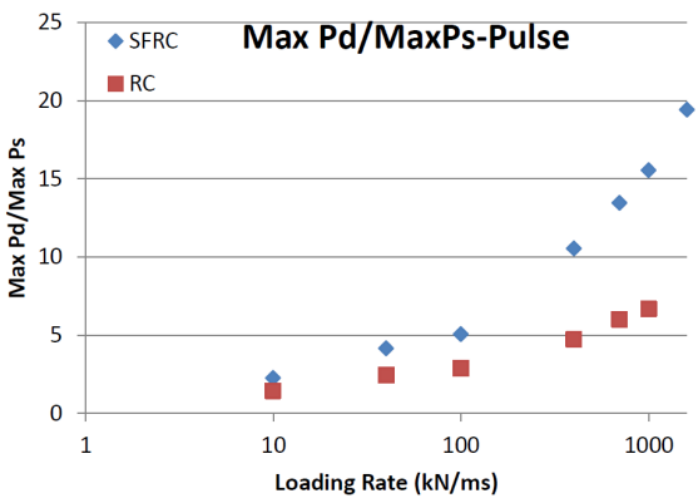

(a)

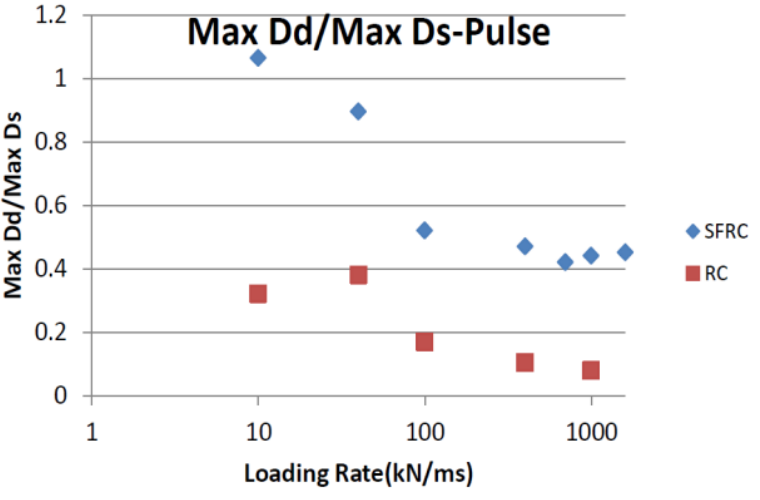

(b)

Figure 9: (a) Comparison of MaxPd/MaxP for RC and SFRC, and (b) Comparison of Max $\delta d / M a x \delta s$ for RC and SFRC under pulse load at different loading rates 


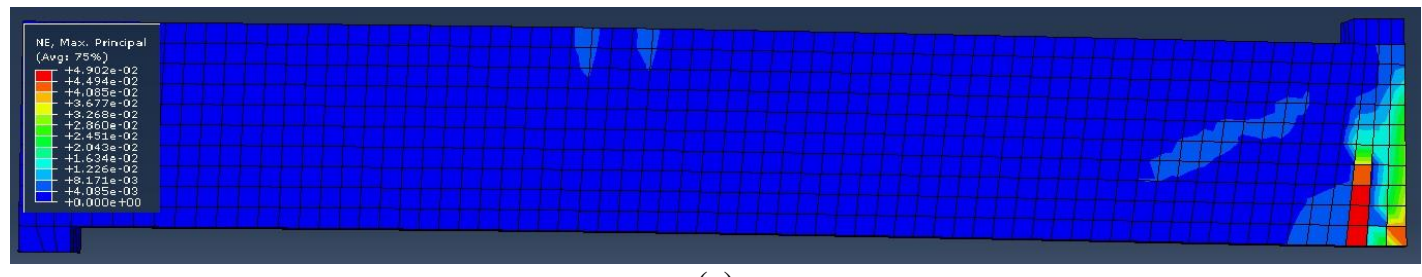

(a)

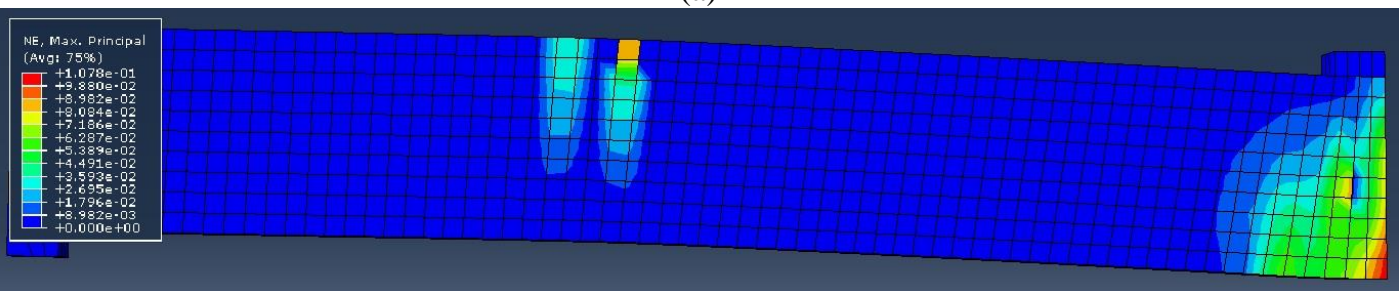

(b)

Figure 10: Strain distribution along SFRC beam for loading rate $100 \mathrm{kN} / \mathrm{msec}$ at (a) $75 \%$ and (b) $100 \%$ of load

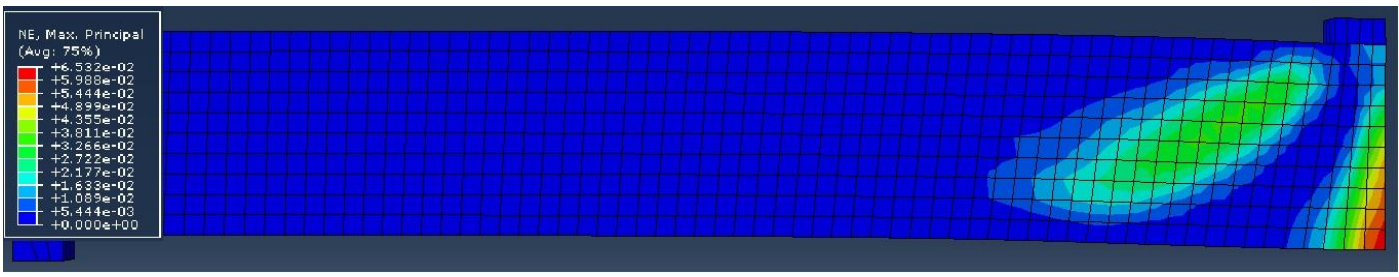

(a)

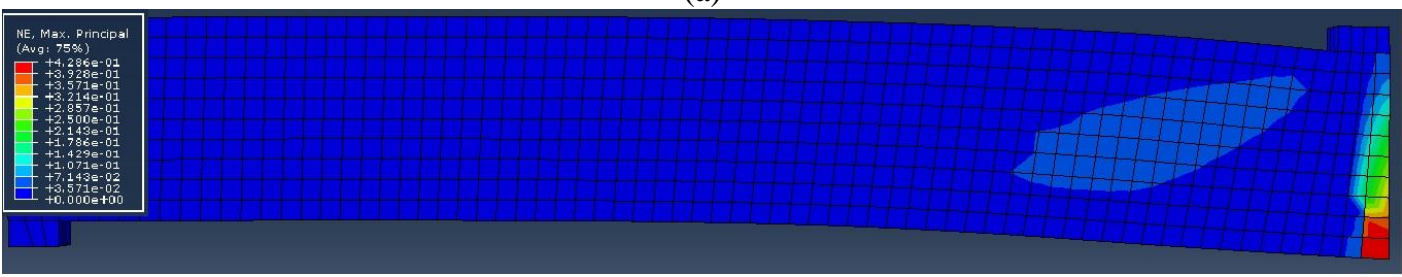

(b)

Figure 11: Strain distribution along SFRC beam for loading rate $1000 \mathrm{kN} / \mathrm{msec}$ at (a) $75 \%$ and (b) $100 \%$ of load

\section{CONCLUSIONS}

A simplified, yet practical, brittle constitutive model was used by the NLFEA program adopted in the present study to analyse the behaviour of RC beams under impact loading applied at the mid span. For the beam case considered, the comparative study between numerical and experimental data revealed that such constitutive models are capable of providing realistic predictions of the experimentally established behaviour of RC beams under increasing rates of loading. The numerical results obtained using ABAQUS NLFEA software on RC beams under different loading rates show good agreement with previous numerical and experimental studies. A comparison of the load-deflection curves under static and impact loads shows that under high-rate loading conditions, the response of both RC and SFRC beams becomes stiffer and allows the beam to attain higher levels of loading. This change in structural response is essentially linked to the deformation profile exhibit by the beams with increasing loading rates which becomes more localised and confined to the mid-span loading region (i.e. the area at which the load is exerted) as the loading rate increases. This is likely to be due to the influence of inertia loads and the nature of stress waves invariably associated with impact which reduce the length of the beam that responds to the applied load. This leads to an in- 
crease of the beam's stiffness and load-carrying capacity as well as to a reduction of its maximum vertical displacement under the load point as the loading rates increase. The study of RC and SFRC beam specimens shows that the use of fibers, at the dosage of $V_{f}=1 \%$ studied, results in significant increase of load carrying capacity and energy absorption of the structural elements under impact. The deflection at the beam mid-span also increases compared to the $\mathrm{RC}$ case indicating the ductility provided by the steel fibres. The extent of the effective length around the point of application of the impact load seems to also improve (albeit still decreasing as the loading rate increases) due to the addition of fibres.

\section{REFERENCES}

[1] D.M. Cotsovos, N.D. Stathopoulos, C. Zeris, Fundamental behaviour of RC beams subjected to high rates of concentrated loading. ASCE Journal of Structural Engineering, 134, 1839-1851, 2008.

[2] D.M. Cotsovos, A simplified approach for assessing the load-carrying capacity of reinforced concrete beams under concentrated load applied at high rates. International Journal of Impact Engineering, 37(8), 907-917, 2010.

[3] S. Saatci, F.J. Vecchio, Nonlinear finite element modelling of reinforced concrete structures under impact loads. ACI Structural Journal, 106(5), 717-725, 2009.

[4] N. Kishi, S.G. Khasraghy, H. Kon-No, Numerical simulation of reinforced concrete beams under consecutive impact loading. ACI Structural Journal, 108(4), 444-452, 2011 .

[5] A.A. Abbas, A.D. Pullen, D.M. Cotsovos, Structural response of RC wide beams under low-rate and impact loading. Magazine of Concrete Research, 62, 723-740, 2010.

[6] I.M. May, Y. Chen, D.R.J. Owen, Y.T. Feng, P.J. Thiele, Reinforced concrete beams under drop-weight impact loads. Computers and Concrete, 3(2-3), 79-90, 2006.

[7] D.M. Cotsovos, M.N. Pavlovic, Modelling of RC Beams under Impact Loading. ICE Proceedings, Structures \& Buildings, 165, 2, 77-94, 2012.

[8] A.A. Abbas, S. Syed Mohsin, D.M. Cotsovos, A.M. Ruiz-Teran, Seismic response of steel fibre reinforced concrete beam-column joints, Engineering Structures, 59, 261-283, 2014.

[9] A.A. Abbas, S. Syed Mohsin, D.M. Cotsovos, A.M. Ruiz-Teran, Shear behaviour of SFRC simply-supported beams, ICE Proc. Structures and Buildings, 167(SB9), 544$558,2014$.

[10] A.A. Abbas, S. Syed Mohsin, D.M. Cotsovos, A.M. Ruiz-Teran, Nonlinear analysis of statically-indeterminate SFRC columns, Structural Concrete, 15(1), 94-105, 2014.

[11] A.A. Abbas, S. Syed Mohsin, D.M. Cotsovos, A.M. Ruiz-Teran, A M, Staticallyindeterminate SFRC columns under cyclic loads, Advances in Structural Engineering, 17(10), 1403-1417, 2014.

[12] ABAQUS Version 6.12-3 Documentation, Available online at http://www.3ds.com/products-services/simulia/products/abaqus (accessed 29/02/2016). 
[13] J.P. Romualdi, G.B. Batson, Mechanics of crack arrest in concrete, Journal of Engineering Mechanics, 89(EM3), 147-168, 1963.

[14] X. Destrée, Steel fibre reinforcement for suspended slabs. Concrete, 35(8),58-59, 2001.

[15] M.P. Nadine, Healthy Doses of Steel Fiber 'Clear' Rebar Congestion in Concrete Coupling Beams. ENR: Engineering News-Record, 266(2), 36, 2011.

[16] British Standard Institution, Eurocode 2: Design of Concrete Structures - Part 1: General Rules and Rules for Buildings. British Standard, DD ENV1992-1-1, 2004.

[17] British Standard Institution, Eurocode 8: Design of Structures for Earthquake Resistance - Part 1: General Rules, Seismic Actions and Rules for Buildings. Bristish Standard, BS EN 1998-1, 2004.

[18] A.E. Naaman, V.S. Gopalaratnam, Impact properties of steel fibre reinforced concrete in bending. International journal of cement composites and lightweight concrete, 5(4), 225-233, 1983.

[19] Z. Xu, H. Hao, H.N. Li, Dynamic tensile behaviour of fibre reinforced concrete with spiral fibres. Materials \& Design, 42, 72-88, 2012.

[20] X.X. Zhang, A.M. Abd Elazim, G. Ruiz, R.C. Yu, Fracture behaviour of steel fibrereinforced concrete at a wide range of loading rates. International Journal of Impact Engineering, 71, 89-96, 2014.

[21] M.N. Pavlović, D.M. Cotsovos, Modelling of RC beams under impact loading. Proceedings of the ICE - Structures and Buildings, 165(2), 77-94, 2012.

[22] M.D. Kotsovos, M.N. Pavlović, D.M. Cotsovos, Characteristic features of concrete behaviour: Implications for the development of an engineering finite-element tool, Computers and Concrete, 5(3), 243-260, 2008.

[23] M.D. Kotsovos, M.N. Pavlović, Structural concrete, Finite-element analysis for limitstate design. Thomas Telford, London, UK, 1995.

[24] J.F. Trottier, N. Banthia, Toughness characterization of steel-fiber reinforced concrete. Journal of materials in civil engineering, 6(2), 264-289, 1994.

[25] P.Robins, S.Austin, P. Jones, Pull-out behaviour of hooked steel fibres. Materials and structures, 35(7), 434-442, 2002.

[26] P.M. Zisopoulos, M.D. Kotsovos, M.N. Pavlovic, Deformational behaviour of concrete specimens in uniaxial compression under different boundary conditions. Cement and concrete research, 30(1), 153-159, 2000.

[27] M.D. Kotsovos, Finite-element Modelling of Structural Concrete: Short-term Static and Dynamic Loading Conditions. Boca Raton, CRC Press, 2015.

[28] O.C. Zienkiewicz, R.L., Taylor, Vol. 2: The Finite Element Method for Solid and Structural Mechanics, $6^{\text {th }}$ Edition. Butterworth-Heinemann, Oxford, UK, 2005. 
[29] G. Hughes, D.M. Spiers, An Investigation on the Beam Impact Problem. Cement and Concrete Association, Technical Report 546, 1982.

[30] T.S. Lok, J.R. Xiao, Flexural strength assessment of steel fiber reinforced concrete. Journal of Materials in Civil engineering, 11(3), 188-196, 1999. 